\section{References}

1. Comoglio C, Boffini M, El Qarra S, Sansone F, D’amico M, Marra S, et al. Aortic valve replacement and mitral valve repair as treatment of complications after percutaneous core valve implantation. J Thorac Cardiovasc Surg. 2009;138:1025-7.

2. Wong DR, Boone RH, Thompson CR, Allard MF, Altwegg L, Carere RG, et al. Mitral valve injury late after transcatheter aortic valve implantation. $J$ Thorac Cardiovasc Surg. 2009;137:1547-9.
3. Marcos-Alberca P, Rey M, Serrano JM, Fernandez-Rozas I, Navarro F, Contreras A, et al. Aneurysm of the anterior leaflet of the mitral valve secondary to aortic valve endocarditis. $J$ Am Soc Echocardiogr. 2000;13:1050-2.

4. Reid CL, Chandraratna AN, Harrison E, Kawanishi DT, Chandrasoma P, Nimalasuriya A, et al. Mitral valve aneurysm: clinical features, echocardiographic-pathologic correlations. J Am Coll Cardiol. 1983;2:460-4.

\title{
Video-assisted anterior approach to Pancoast tumors
}

\author{
Philip A. Linden, MD, Cleveland, Ohio
}

Significant advances in the treatment of Pancoast tumors have been made over the past 50 years. Some advances have been in neoadjuvant treatments, whereas others have been in surgical technique. The classic approach to Pancoast tumors involves a posterolateral thoracotomy extending posteriorly to the base of the neck. With tumors invading the anterior aspects of the first rib or subclavian artery or vein, an anterior approach is helpful. Dartevelle and colleagues ${ }^{1}$ pioneered the anterior cervicothoracic approach with an L-shaped incision paralleling the anterior border of the sternocleidomastoid muscle down the midline to the level of the second or third ribs, extending laterally to the deltopectoral groove. The medial clavicle is resected. Excellent exposure of the subclavian vessels, anterior aspects of ribs, and brachial plexus is possible through this incision. Lobectomy is performed after detachment of the chest wall. Grunenwald and Spaggiari ${ }^{2}$ described a clavicle-sparing modification of the anterior approach involving detachment and elevation of the clavicle with an attached portion of sternum to gain access to the first rib and thoracic inlet. With either approach, a simultaneous posterolateral thoracotomy has been advocated for completing the upper lobectomy and nodal dissection. ${ }^{3}$

Described here is the novel use of video-assisted thoracic surgery (VATS), rather than thoracotomy, to dissect the pulmonary vessels and perform a nodal dissection after chest wall resection via the anterior, clavicle-sparing approach. The VATS approach is of greatest utility when there is limited invasion of the apical chest wall (Figure 1).

From the Division of Thoracic and Esophageal Surgery, Case Medical Center/University Hospitals, Case Western Reserve School of Medicine, Cleveland, Ohio.

Disclosures: None.

Received for publication Oct 15, 2009; revisions received March 1, 2010; accepted for publication March 12, 2010; available ahead of print April 19, 2010.

Address for reprints: Philip A. Linden, MD, 11100 Euclid Ave, Cleveland, OH $44106-$ 5011 (E-mail: philip.linden@uhhospitals.org).

J Thorac Cardiovasc Surg 2010;140:e38-9

$0022-5223 / \$ 36.00$

Copyright (c) 2010 by The American Association for Thoracic Surgery doi: $10.1016 /$ j.jtcvs. 2010.03 .007

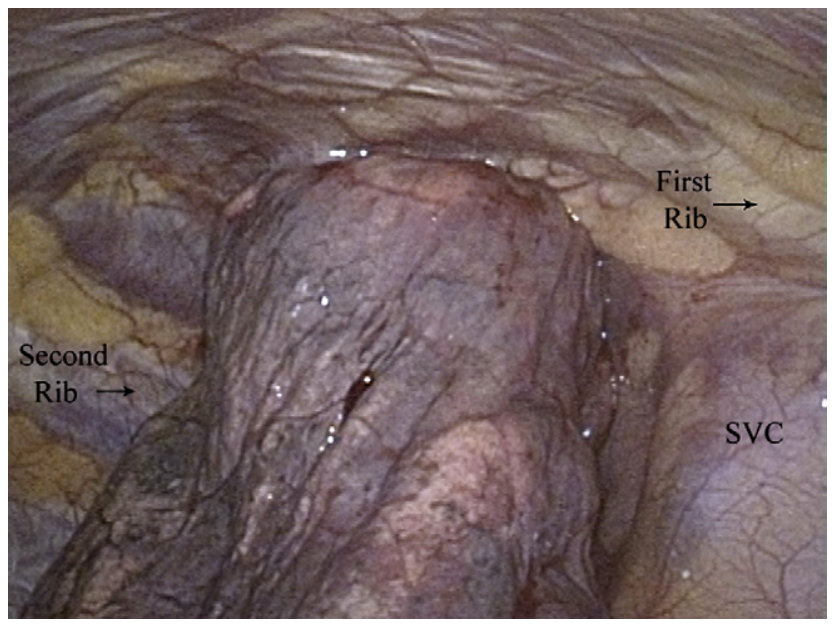

FIGURE 1. Thoracoscopic view of a Pancoast tumor invading the thoracic inlet at the level of the first rib and above.

\section{TECHNIQUE}

The patient is placed in the supine position with a vertical roll under the lateral chest elevating the operative side. The arm is rested posteriorly behind the roll on the operating room table. An incision is made from the inferior edge of the anterior border of the sternocleidomastoid muscle, down the midline of the sternum, to the top of the second rib extending laterally over the border of the second rib (Figures 2 and 3). The pectoral muscle is lifted off the chest wall. The sternum is divided in the midline from the level of the sternal notch to the top of the second rib. An oscillating saw is used to "T-off" the sternal incision. A blunt right angle is used to dissect between the head of the clavicle and the insertion of the first rib, and a Gigli saw is used to detach the insertion of the first rib into the sternum. A blunt periosteal elevator can be used to dissect the subclavian vessels away from the clavicle, and the clavicle is retracted anteriorly. The subclavian vein, anterior scalene muscle, and subclavian artery are inspected, and if there is no invasion, they are dissected away from the first rib with a blunt periosteal elevator. The posterior aspect of the first rib is divided. 


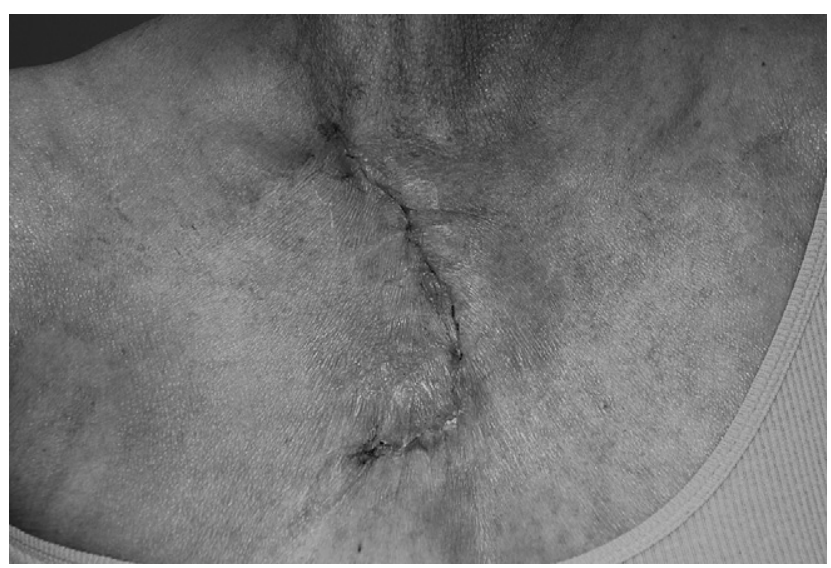

FIGURE 2. The incision for anterior Pancoast approach. An additional 10 -mm camera port incision is not shown.

The upper lobe is now free of the chest wall. A $10-\mathrm{mm}$ incision is made in the anterior axillary line in the sixth intercostal space for video assistance. On the right side, the truncus anterior and upper lobe pulmonary vein can be dissected with traditional instruments inserted through the sternal incision with videoscopic visualization. The anterior fissure is partially completed along with division of the ascending artery to the posterior segment of the right upper lobe. The right upper lobe bronchus is divided with an endoscopic stapler, which can be inserted through the anterior incision, and the posterior aspect of the fissure is completed. A right paratracheal nodal dissection can be performed under direct vision. A complete subcarinal nodal dissection requires video assistance. A single chest tube is placed through the camera port. The sternum is reapproximated with 3 wires.

\section{DISCUSSION}

For anteriorly based Pancoast tumors, an anterior approach best allows for assessment of the subclavian vessels, with resection and reconstruction, if needed. If only the first rib is removed, visualization of the hilum and subcarinal areas is not possible through the primary, anterior incision. Even if the second rib is removed, visualization is difficult. Videoscopic assistance allows safe hilar dissection and a thorough nodal dissection through the primary incision. If ribs 1 to 3 are resected, then hilar dissection and complete lymphadenectomy can be performed through the anterior incision without the addition of a posterolateral thoracotomy. Although this procedure described herein concerns a rightsided resection, VATS is potentially of even greater benefit

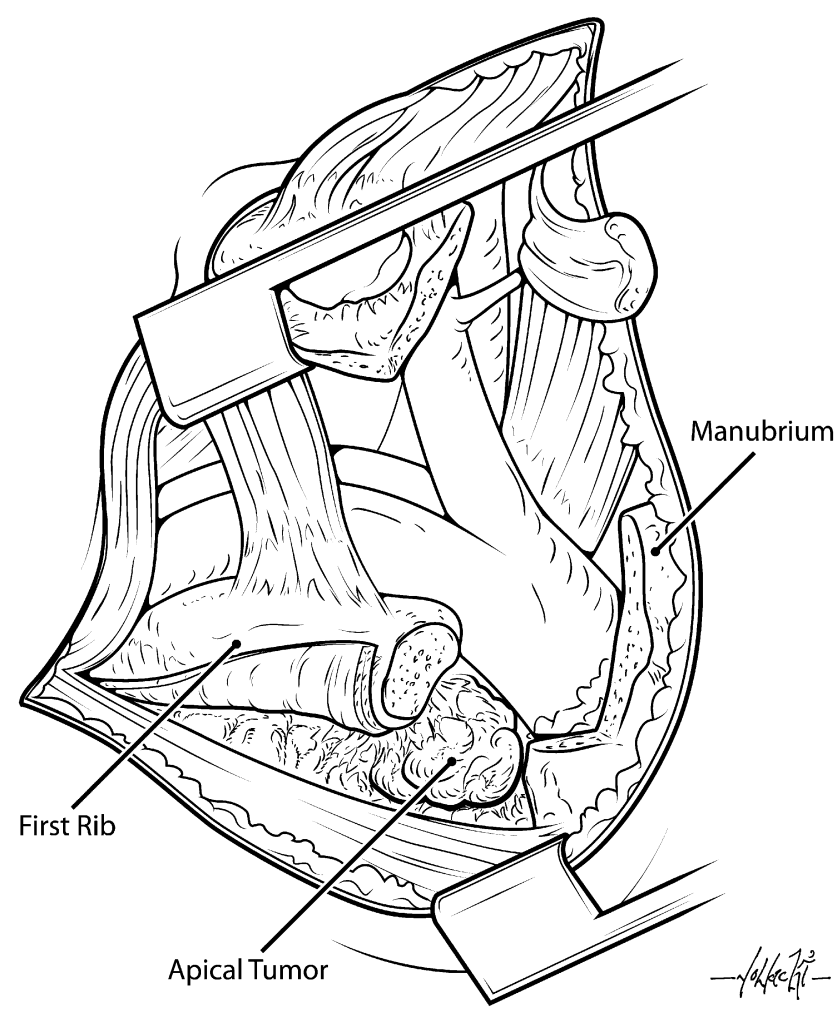

FIGURE 3. Line drawing showing the incision, the L-shaped division of the manubrium, detached first rib and intercostal muscle, subclavian vessels, and tumor attached to the first rib.

for left-sided apical resections as the pulmonary arterial branching is more complex on the left than on the right.

Resection and reconstruction of the subclavian vessels and dissection of tumor away from the brachial plexus can be performed through the partial sternotomy incision with extension into the neck. Invasion of the vertebral body would not be amenable to VATS dissection and would require a posterolateral thoracotomy. The pain after an anterior approach via partial sternotomy is very manageable. It can generally be controlled with oral narcotics starting on the first postoperative day.

\section{References}

1. Dartevelle P, Chapelier A, Macchiarini P, Lenot B, Cerrina J, Ladurie FL, et al. Anterior transcervical-thoracic approach for radical resection of lung tumors invading the thoracic inlet. J Thorac Cardiovasc Surg. 1993;105:1025-34.

2. Grunenwald D, Spaggiari L. Transmanubrial osteomuscular sparing approach for apical chest tumors. Ann Thorac Surg. 1997;63:563-6.

3. Vanakesa T, Goldstraw P. Antero-superior approaches in the practice of thoracic surgery. Eur J Cardiothoracic Surg. 1999;15:774-80. 